\title{
Variations of the alpine precipitation from an ice core record of the Laohugou glacier basin during 1960-2006 in western Qilian Mountains, China
}

\author{
QIN Xiang ${ }^{1}$, CUI Xiaoqing ${ }^{1}$, DU Wentao ${ }^{1}$, DONG Zhiwen $^{1}$, REN Jiawen $^{1}$, \\ CHEN Jizu ${ }^{1,2}$
}

1. State Key Laboratory of Cryospheric Sciences, Cold and Arid Regions Environmental and Engineering Research Institute/Qilian Shan Station of Glaciology and Ecologic Environment, CAS, Lanzhou 730000, China;

2. Resource and Environment College of Lanzhou University, Lanzhou 730000, China

\begin{abstract}
The net accumulation record of ice core is one of the most reliable indicators for reconstructing precipitation changes in high mountains. A $20.12 \mathrm{~m}$ ice core was drilled in 2006 from the accumulation zone of Laohugou Glacier No.12 in the northeastern Tibetan Plateau, China. We obtained the precipitation from the ice core net accumulation during 1960-2006, and found out the relationship between Laohugou ice core record and other data from surrounding sites of the northeastern Tibetan Plateau. Results showed that during 1960-2006, the precipitation in the high mountains showed firstly an increasing trend, while during 1980 to 2006 it showed an obvious decreasing trend. Reconstructed precipitation change in the Laohugou glacier basin was consistent with the measured data from the nearby weather stations in the lower mountain of Subei, and the correlation coefficient was $0.619(P<0.001)$. However, the precipitation in the high mountain was about 3 times more than that of the lower mountain. The precipitation in Laohugou Glacier No.12 of the western Qilian Mountains corresponded well to the net accumulation of Dunde ice core during the same period, tree-ring reconstructed precipitation, the measured data of multiple meteorological stations in the northeastern Tibetan Plateau, and also the changes of adjacent PDSI drought index. Precipitation changes of the Laohugou glacier basin and other sites of the northeastern Tibetan Plateau had significantly positive correlation with ENSO, which implied that the regional alpine precipitation change was very likely to be influenced by ENSO.
\end{abstract}

Keywords: alpine precipitation; ice core; Laohugou Glacier No.12; Qilian Mountains

\section{Introduction}

In global change research, the data of alpine precipitation change are very scarce, and the net accumulation record of ice core is one of the most reliable indicators for reconstructing pre-

Received: 2014-04-16 Accepted: 2014-05-16

Foundation: National Natural Science Foundation of China, No.41371091; No.41201067; No.41301064; National Basic Research Program of China, No.2013CBA01801

Author: Qin Xiang, Associate Professor, specialized in glaciology and global change research. E-mail: qinxiang@lzb.ac.cn 
cipitation changes in the high mountains (Yao et al., 1996a). We can obtain precipitation records in the glacier area by reconstructing net accumulation of the ice core, and then to better understand the local climate change history (Yao et al., 1996b; Thompson et al., 2000; Qin et al., 2002; Sun et al., 2012). On the Tibetan Plateau, researchers have drilled some longer ice cores such as Dude, Tanggula, Guliya, Dasuopu and East Rongbuk since the 1980s, and then restored and discussed the accumulation of these ice cores to reconstruct regional precipitation change (Yao et al., 1990, 1999; Hou et al., 1999, 2000). Under the influence of altitude and local terrains, there exists great difference between the precipitation in glacier area and the surrounding plains, and low altitude mountains. The precipitation study in high mountains is of great significance to global change research. The change of precipitation in high mountains is affected by many factors, and thus reconstruction of precipitation is much more difficult than that of air-temperature. Precipitation information was well preserved in the alpine ice cores, and ice core is one of the most reliable and direct records to reconstruct past precipitation (Duan et al., 2008; Dong et al., 2013; Wang et al., 2013). At the same time, the high-resolution records of ice core accumulation ensured the continuous precipitation in global change research (Yao et al., 1996b).

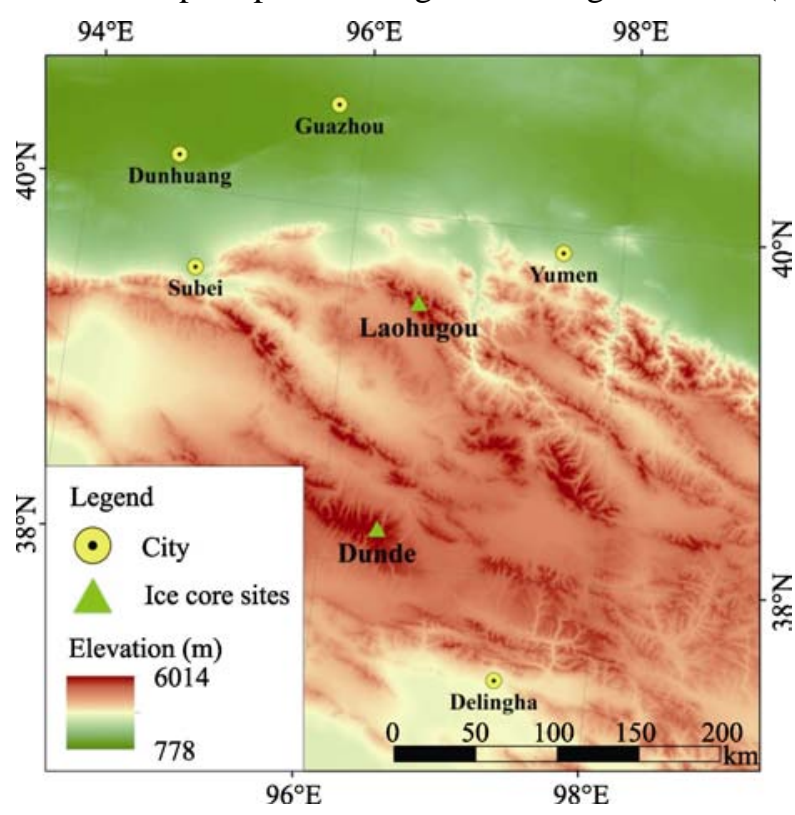

Figure 1 Location map showing Laohugou Glacier No.12 in the western Qilian Mountains, China
The Qilian Mountains are located at the northeast edge of the Tibetan Plateau. Many inland rivers originated from the mountains. It is one of the most important catchment areas in Hexi Corridor of Northwest China (Figure 1). Therefore, understanding the climate change in historical period of the Qilian Mountains is particularly important, especially for the history of drought change. However, the historical data of precipitation change is very scarce in high-altitude glacier area of the Qilian Mountains, and the precipitation change of the alpine glacier area is still unclear. This paper mainly focuses on an ice core of $20.12 \mathrm{~m}$ in depth, drilled in the accumulation zone of the typical continental glacier, Laohugou Glacier No.12, on the northern slope of the western Qilian Mountains. We reconstructed nearly 46 years change of the precipitation by net accumulation record of the ice core, and analyzed the precipitation change in the high-altitude glacier area. Furthermore, this study will provide important basis for the research of precipitation record of future deep ice cores in this region.

\section{Data source and method}

\subsection{Sampling in the field work}

There are many mountain glaciers in the high elevation regions of the Qilian Mountains. The 
Laohugou region is located on the northern slope of the western Qilian Mountains (39 $05^{\prime}-$ $39^{\circ} 40^{\prime} \mathrm{N}, 96^{\circ} 07^{\prime}-97^{\circ} 04^{\prime} \mathrm{E}$ ). This region is of typical continental climate. Among the glaciers of the Laohugou basin, Glacier No.12 is the largest valley glacier in the western Qilian Mountains. The length and area of the glacier is $9.85 \mathrm{~km}$ and $20.4 \mathrm{~km}^{2}$, respectively (Du et al., 2008; Cui et al., 2011; Sun et al., 2012). Glacier No.12 is the most representative glacier of the western Qilian Mountains, and is composed by the eastern and western branches. The research on Laohugou No.12 Glacier began in 1958, and the nearby glacier station is one of the earliest stations for glaciological research in China. During 1958 to 1962, researchers monitored glacier meteorology, hydrology, mapping, mass balance, the process of snow to ice and ice temperature etc. But the station was closed in 1962 for glaciological flood. Only in the 1970s-1980s, some short-time observations were carried out for studies on the change of glaciers and its influence on the water source. The Qilian Shan Station of Glaciology and Ecologic Environment was rebuilt in 2005, and thus we restart to continually observe the change of the Laohugou Glacier No.12.

In June 2006, a $20.12 \mathrm{~m}$ shallow ice core was drilled from the accumulation zone of Laohugou Glacier No.12 (39²5.7'N, 96 33.4'E, 5040 m a.s.l.). Meanwhile, we dug two snow pits with depths of $95 \mathrm{~cm}$ (26 snow samples) and $140 \mathrm{~cm}$ (34 snow samples), respectively. Meteorological observation data shows that, the average annual temperature of the ice core drilling site is very low (less than $-10^{\circ} \mathrm{C}$ ), so we can infer that the ice core record was preserved very well. The ice core was then transported to the State Key Laboratory of Cryospheric Science of the Chinese Academy of Sciences in Lanzhou, and was stored in a frozen condition until analysis.

\subsection{Experiments and analysis method}

The ice core cut and measurements were performed under class 100 conditions in the laboratory at very low temperature $\left(-15^{\circ} \mathrm{C}\right)$, and was cut into $3 \mathrm{~cm}$ samples in length firstly. A total of 606 samples spanning the period 1960-2006 were obtained. A $1 \mathrm{~cm}$ outer layer was removed by a stainless steel spade for the stable isotope test. The inner ice samples were placed in sample vases which were washed with ultra-pure water. The samples were then stored in the cold storage $\left(-18^{\circ} \mathrm{C}\right)$. The major ions of the ice core and snowpits samples were determined with an ICS-2500 Ion Chromatography (Dionex Company). The test error is less than $1 \%$, and the limits of all ions are less than $1 \mathrm{ng} / \mathrm{g}$ (Cui et al., 2011). Before analysis, the samples were removed from the laboratory freezer and allowed naturally melting. All operations were carried out under class 100 conditions in clean environment, and strict control of the analysis process was ensured in order to avoid possible contamination. Stable oxygen isotope ratios $\left(\delta^{18} \mathrm{O}\right)$ were analyzed using a MAT-253 mass spectrometer, with a precision of $0.02 \%$. $\beta$ activation grade was analyzed using a MINI20 type low background $\alpha / \beta$ counting system.

The ice core was dated using a multi-parameter combined method. Based on the seasonal change of the major ions such as $\mathrm{Ca}^{2+}, \mathrm{SO}_{4}{ }^{2-}$ and $\delta^{18} \mathrm{O}$, and characteristics of the dust layer of the $20.12 \mathrm{~m}$ shallow ice core, verification was done in 1963 by $\beta$ activity peaks as a result of the atmospheric thermonuclear test in the early 1960s (Cui et al., 2011). Thus we dated the chronosequence of the ice core is from 1960 to 2006 (Figure 2). In addition, this research uses the temperature and precipitation data of the Subei Station which is adjacent to the 
Laohugou Glacier area, and other weather stations in the piedmont plain. Meteorological data is derived from the Chinese National Meteorological Information Center (http://www.nmic.gov.cn/). The temperature and precipitation data of weather stations in the Yellow River source area of the northeastern Tibetan Plateau came from Duan et al. (2008). It uses the site average climate sequence to represent the local climate sequence. The recent reconstructed accumulation of Dunde ice core came from Yao et al. (1990) and Hou et al. (2000). The accumulation data of the Dongkemadi glacier in the corresponding period is from research of Zhang et al. (2007). Compared with these records, reconstructed results of this work were used to analyze the spatial differences of precipitation in the northeastern Tibetan Plateau.

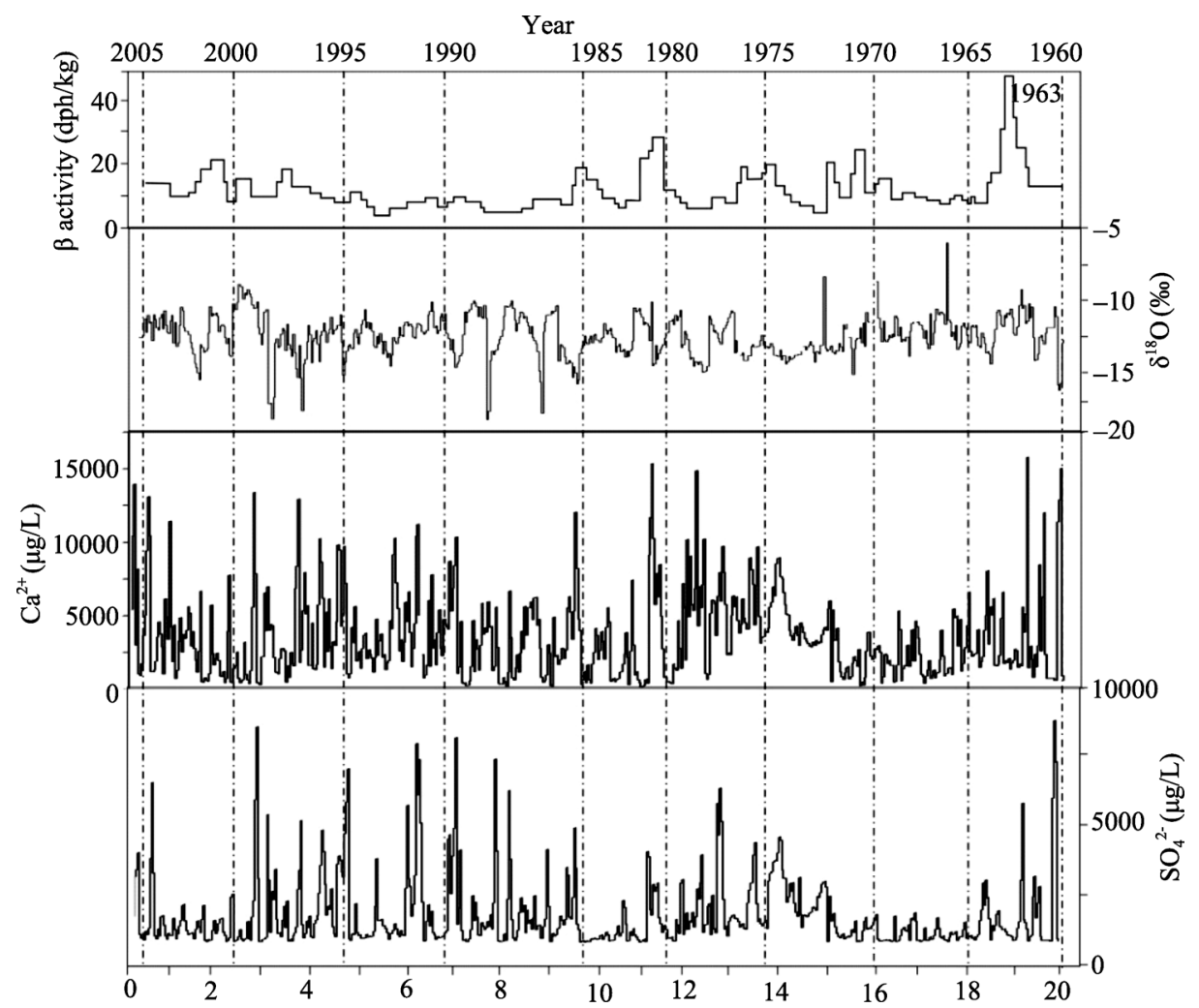

Figure 2 Dating result of the ice core from Laohugou Glacier No.12

Due to the lack of precipitation data in high-altitude area, the net accumulation of glacier becomes one of the most reliable indicators to reflect the historical precipitation in high-altitude regions. However, the estimate of glacier net accumulation may be affected by surface evaporation and sublimation, so it is necessary to evaluate and determine the extent of such effect. Therefore, we collect samples of snow pits, and use the observed data of the automatic weather station of $5040 \mathrm{~m}$ a.s.l. to verify the above results, and to obtain the influence of evaporation and sublimation in the glacier accumulation. According to the accumulation and density of snow pit in 2011, we acquired the precipitation of that year is 398 $\mathrm{mm}$ in water equivalent. The calibrated value of the measured precipitation is $403 \mathrm{~mm}$, which is observed by the nearby automatic meteorological station. Both of them are relatively consistent, and the error is less than $2 \%$. This reflects that the sample point of ice core in this glacier is little affected by sublimation and evaporation. Probably, it may be due to 
the altitude of the sample point is very high and the temperature is very low, as the observed data in 2011 showed that the annual average temperature of the $5040 \mathrm{~m}$ a.s.l. is $-12^{\circ} \mathrm{C}$. Thus in this work the influence of sublimation and evaporation is not discussed in detail.

Meanwhile, we found that there is obviously positive correlation between the change of air temperature and the $\delta^{18} \mathrm{O}$ in the snow pit. During the high temperature season, the value of $\delta^{18} \mathrm{O}$ is also high (Figure 3a). Using the $\delta^{18} \mathrm{O}$ value of the ice core in Laohugou, we restored the change of air temperature from 1960 to 2006 in the glacier area (Figure 4a). It has
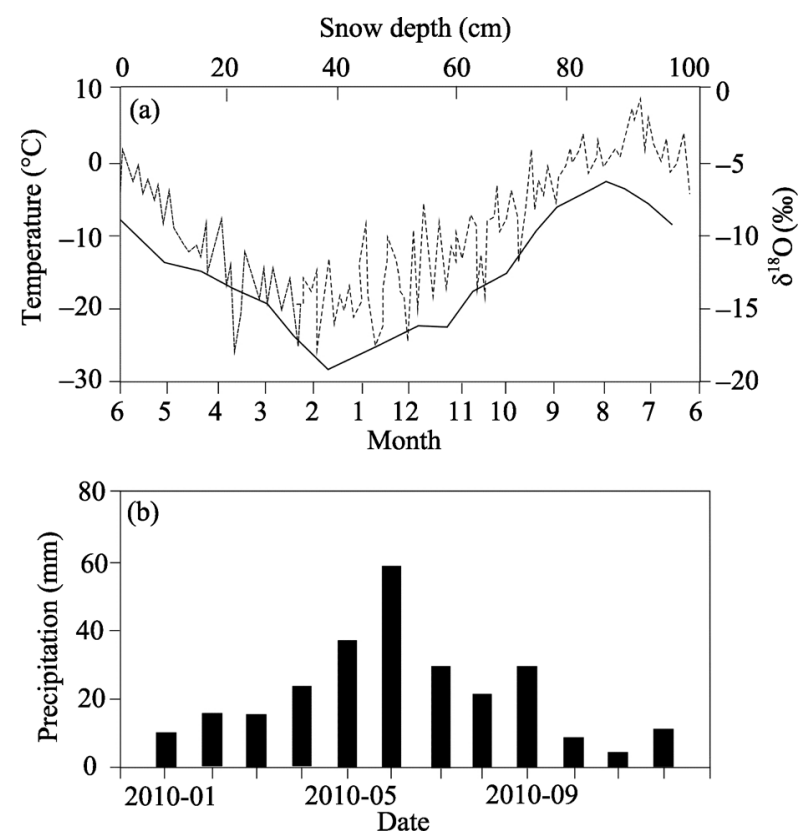

Figure 3 Observed air temperature variation in accumulation zone (a), and monthly precipitation change (b), in Laohugou Glacier No.12 in 2010
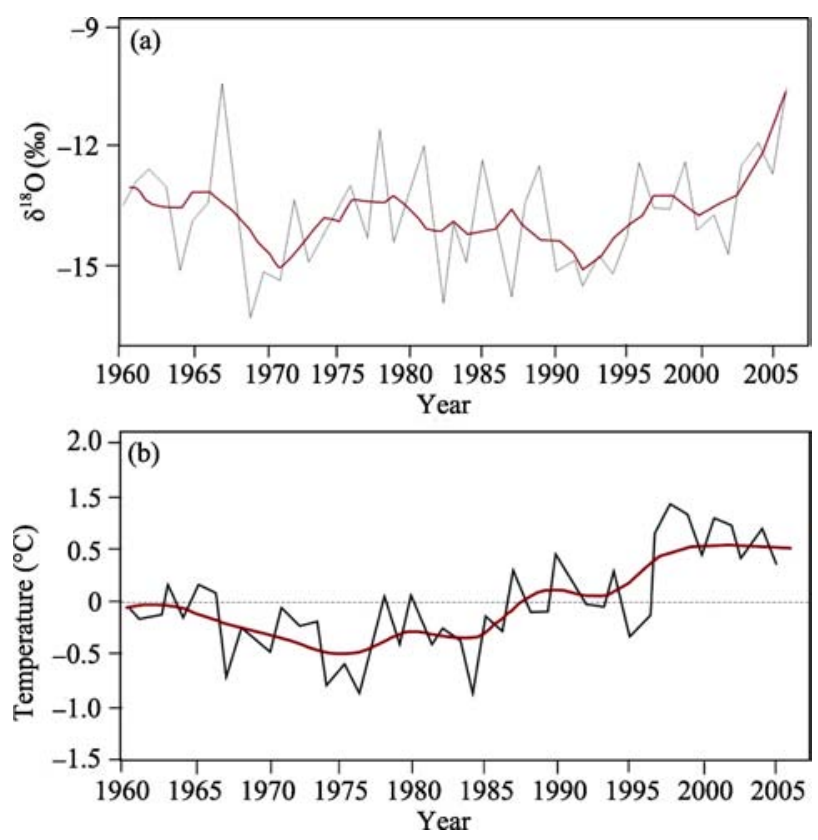

Figure 4 Variation of the $\delta^{18} \mathrm{O}$ record in ice core (a), and air temperature change at Subei Station (b) 
a good positive correlation with the air temperature change of Subei Station in low mountain area (Table $1, \mathrm{R}=0.643, P<0.001$ ). However, the change extent of ice core reconstructed air temperature in glacier area is relatively small (Figure 4b). Compared with the rising of air temperature in low mountain area in Subei, the result of Laohugou shows relatively small change extent of temperature in the glacier area during the past 46 years (Cui et al., 2011). Previous study has indicated that the temperature rising on the glaciers in the Everest of the southern Tibetan Plateau, has significantly affected the changes of glacier mass balance, and thus the increased glacier ablation, causing the great glacier retreat, while the accumulation change of ice core obtained in accumulation zone was mainly affected by the precipitation (Hou et al., 1999). The temperature change of glacier area is relatively stable in this study, and thus we can infer that the temperature has little influence on the accumulation records. This result demonstrates that the influencing factors of the accumulation change in glacier area of high altitude have the common features in the northern and southern Tibetan Plateau. From 1960 to 2006, the equilibrium line altitude of the Laohugou Glacier No.12 showed a rising trend (Table 2). Moreover, the equilibrium line altitude (ELA, its upper limit is 4950 $\mathrm{m}$ a.s.l.) was lower than the elevation of the ice core drilling site. Therefore, there exists little melting, and the net accumulation of the Laohugou ice core can well reflect the precipitation of the alpine glacier area. Primary observation results showed that the error was less than $2 \%$.

Table 1 Correlations of temperature and precipitation between Laohugou basin and surrounding stations

\begin{tabular}{ccccc}
\hline Laohugou ice core & Low mountain & \multicolumn{3}{c}{ Piedmont plain } \\
\cline { 2 - 5 } & Subei & Yumen & Anxi & Dunhuang \\
\hline Air temperature from $\delta^{18} \mathrm{O}$ & $0.643^{*}$ & $0.671^{*}$ & $0.643^{*}$ & 0.521 \\
Precipitation from accumulation & $0.619^{*}$ & 0.520 & 0.365 & 0.401 \\
\hline
\end{tabular}

$* P<0.001$

\section{Results and discussion}

\subsection{Reconstruction of the alpine pre- cipitation and its comparison with other records in surrounding regions}

Based on the annual layer thickness of ice core and the average density of the corresponded annual layers, we can obtain the net accumulation of the ice core. To eliminate the influence of the ice core
Table 2 Variation of the equilibrium line altitude (ELA) of the Laohugou Glacier No.12 from 1959 to 2006

\begin{tabular}{ccc}
\hline Year & $\begin{array}{c}\text { Altitude of equilib- } \\
\text { rium line (m a.s.l.) }\end{array}$ & References \\
\hline 1959 & 4800 & Kang et al., 1981 \\
1960 & 4900 & Kang et al., 1981 \\
1961 & 4950 & Kang et al., 1981 \\
1975 & 4780 & Kang et al., 1981 \\
1976 & 4700 & Kang et al., 1981 \\
2006 & 4900 & Du et al., 2008 \\
\hline
\end{tabular}
dating to the inter-annual variability of net accumulation, we calculated the five-year moving average for the reconstructed net accumulation of the Laohugou ice core. Figure 5 shows the precipitation change of high-altitude glacier area (Figure 5a), which is reconstructed by the net accumulation of the Laohugou ice core, and also the observed meteorological data and the precipitation records of other ice cores in corresponding period of the surrounding areas in northeastern Tibetan Plateau (Figure 5b-e). The results of ice core showed that, the average precipitation of the glacier accumulation zone was $310 \mathrm{~mm}$ in the Laohugou Glacier 
No.12 over the past 46 years (Table 3 ), and the variation coefficient of precipitation is $41 \%$. The precipitation of alpine glacier area firstly increased, and then decreased. From 1960 to 1980 , the precipitation showed an obviously increasing trend. While from 1980 to 2006, it showed an obviously decreasing trend. The reconstructed precipitation change in the alpine glacier area has a good consistent with the observed precipitation in the nearest weather station of lower mountain of Subei county (Figure 5b). The correlation coefficient is equal to $0.619(P<0.001)$, and both of them showed a decreasing trend since 1980. However, the precipitation in high mountain area is about 3 times than that in the lower mountain of Subei county. The average annual precipitation of Subei station is about $100 \mathrm{~mm}$. Moreover, reconstructed precipitation of the ice core was well consistent with the observed precipitation in 2010 (about $400 \mathrm{~mm}$, Figure 3b) at Laohugou Glacier No.12. Meanwhile, the net accumulation of Laohugou ice core is well corresponded to the glacier accumulation of Dunde ice core (Figure 5d), and the Geladandong ice core in Tanggula mountain (Zhang et al., 2007), and the observed average precipitation of multiple weather stations in the Yellow River source region of the northeastern Tibetan Plateau (Figure 5c), and also the change process of PDSI (Palmer Drought Severity Index) in the same period from 1960 to 2006 of the study area (Dai et al., 2004, 2011; Figure 5e). Although the change process of these records is slightly different, this may be caused by the difference between the elevation and local climate conditions at various
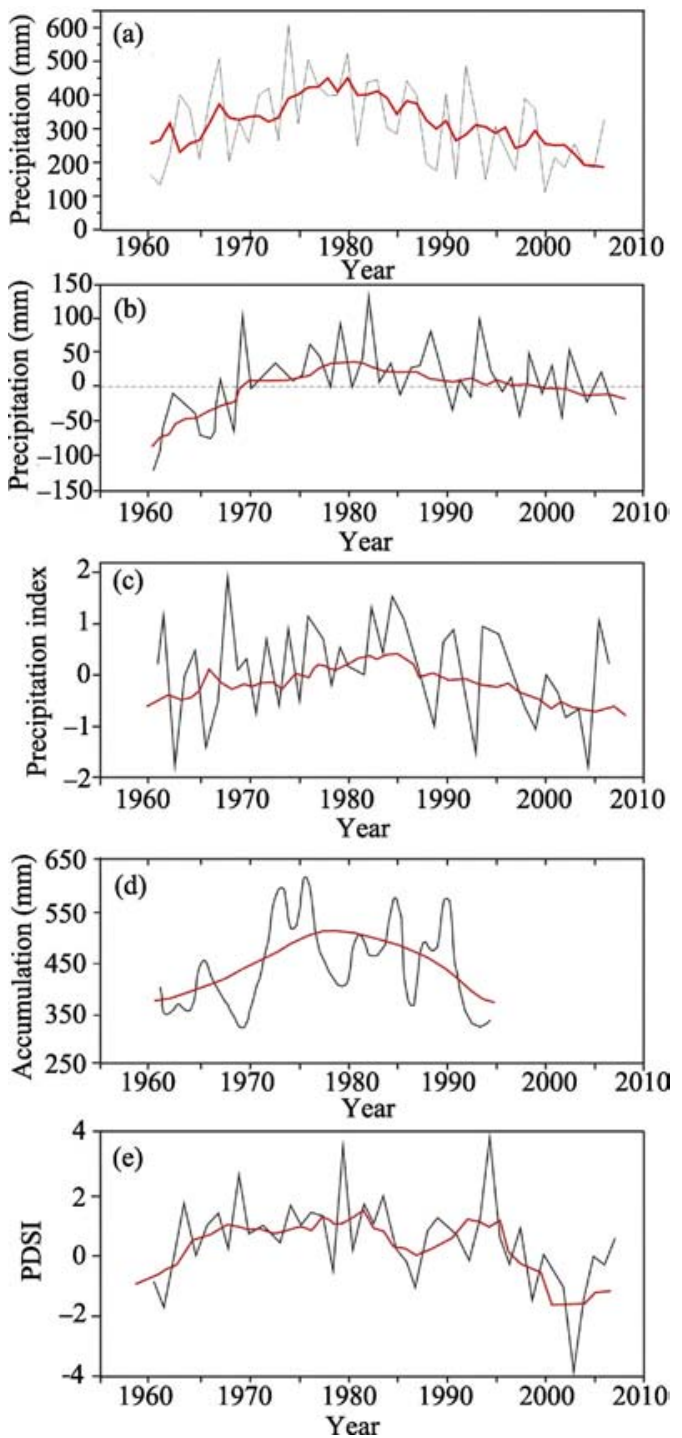

Figure 5 Comparison of Laohugou ice core with other data from observation, ice core and tree ring in surrounding sites of the northeastern Tibetan Plateau. (a) Precipitation from Laohugou ice core; (b) precipitation observed at Subei Station; (c) precipitation observed at Yellow River source stations; (d) precipitation from Dunde ice core; (e) the adjacent PDSI index. The moving average is all 5-year value except that (d) is of 11-year

study sites. However, the variation trend of precipitation at these sites all changed around 1980, and showed an obvious increasing trend firstly and then decreasing trend. The average annual precipitation change has a change point in the early 1980 at multiple meteorological stations of the Yellow River source area. From 1961 to 1983, the precipitation showed an increasing trend, while it showed an obvious decreasing trend after 1983 (Duan et al., 2008).

Dunde ice core is the biggest ice cap located in the western Qilian Mountains. Yao et al. 
Table 3 Statistics of precipitation reconstructed from the Laohugou ice core during 1960-2006

\begin{tabular}{cc}
\hline Precipitation & Values \\
\hline Mean $(\mathrm{mm})$ & 310.18 \\
Sd (mm) & 125.97 \\
Se & 18.37 \\
Median (mm) & 305 \\
Coef Var (\%) & 41 \\
Max (mm) & 606.8 \\
Min (mm) & 85 \\
Range (mm) & 521.8 \\
Year & 47 \\
\hline
\end{tabular}

(1990) has studied the precipitation changing trend of the Dunde ice core since the early 17 th century. Our result is well consistent with the precipitation change of Dunde ice core in the same period; however, the precipitation value is obviously different. Although the Laohugou ice core is only hundreds kilometers away from the Dunde ice core, the average precipitation of Dunde ice core record was obviously higher than that of the Laohugou ice core during 1960 to 1990 (Figure 5d), reflecting the

great influence of the elevation and local environment on the precipitation change of the northern Tibetan Plateau, as the drilling site of Dunde ice core is with altitude of $5325 \mathrm{~m}$ a.s.l.

Previous study showed that, the relative humidity did not decrease with the rising of altitude on the Tibetan Plateau, but increased with altitude rise within a certain height and reached the maximum value at about $400 \mathrm{hPa}$, and it then began to decrease with the altitude rise (Yao et al., 1999). Moreover, some study showed that, the accumulation of ice core record in the Tibetan Plateau has the reverse change characteristics between the southern and northern Tibetan Plateau. This may be related to the dynamic drive of the climatic system, such as the variation of the North Atlantic Oscillation (NAO, Hou et al., 2000). The adjacent PDSI drought index of the study area in the western Qilian Mountains also indicated that the drought-wet change of this period (1960-2006) is reliable, as the drought index has showed an obvious decreasing trend since 1980. The result further showed that, the precious research sites and meteorological data reflected synchronization and consistency variation of precipitation in the northeast Tibetan Plateau, which may be affected and driven by similar climate system and need to be further analyzed and validated.

Dunde ice core and Subei weather station are the sites adjacent to the Laohugou glacier basin in the western Qilian Mountains, which are located on the northern and southern slopes of the western Qilian Mountains, respectively. The precipitation consistency between these records and the Laohugou ice core accumulation (the corresponding period of Dunde is from 1960 to 1990) may imply that, the Laohugou ice core record is of representative to the precipitation change of the western Qilian Mountains. Compared with meteorological data of low mountain (Subei Station), the net accumulation of Laohugou ice core reflects the precipitation changing trend of reduction more obviously around 1980 (Figure 5a), which indicates that the ice core record of the alpine glacier may be more sensitive to regional climate change. Compared with the low altitude precipitation records, the change extent of the ice core accumulation is more significant. In addition, the precipitation change form tree ring record in Delingha region on the southern slope of the lower mountainous area in the western Qilian Mountains reveals that, from 1960 to 1990 the precipitation in Delingha region showed an increasing trend, however, during the period of 1990-2001 it showed an obviously decreasing trend (Shao et al., 1990; Dong et al., 2012). Such a change is similar 
with our study results; while the start time of the precipitation reduction in Delingha is obviously lag. This lag might be caused by local environment. Delingha is located in the Qaidam Basin, which has different geographical environment compared to the high altitude regions of the western Qilian Mountains.

We also compared the correlation between the ice core record and air temperature and precipitation data of the surrounding weather stations in low mountains and the piedmont plain of the Qilian Mountains (see Table 1). The results show that, the air temperature and precipitation change of the ice core record has a good positive correlation with the data observed in the low mountains (Subei). Although the temperature change of other three weather stations in plain regions (lower than $1600 \mathrm{~m}$ a.s.l.) is well consistent with the result of Laohugou $(P<0.001)$, there is a large discrepancy of the precipitation change between the high mountains and the plain regions, and the positive correlation is not very obvious. Maybe these stations are far away from the Laohugou glacier basin, and are located in the lower altitude regions of the Hexi corridor. The precipitation mechanism may have large difference, so their precipitation change is not well consistent with the glacier area from 1960 to 2006. This also reflects the complexity of regional precipitation change in alpine mountains.

\subsection{Relationship between the precipitation change and ENSO}

Figure 6 shows the comparison of precipitation change of the Laohugou glacier basin and the ENSO index. Previous studies showed that, ENSO may be the driving factor of climate
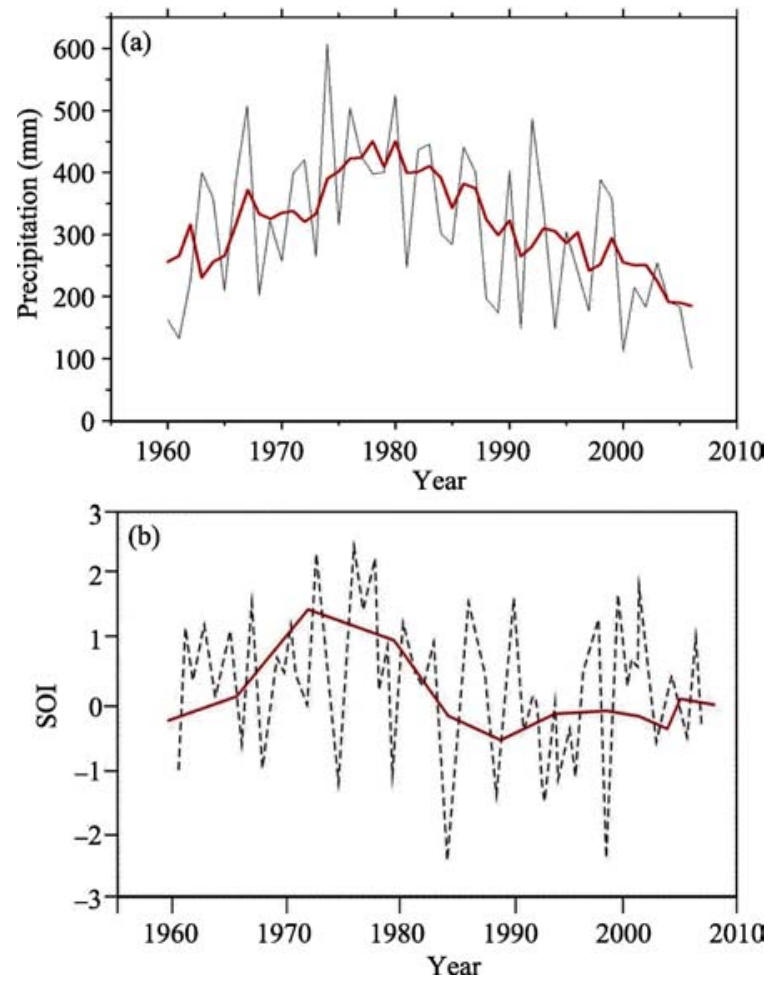

Figure 6 Reconstructed alpine precipitation change in Laohugou during past 50 years (a. the red line is 5-year moving average), and corresponding SOI change (b. the red line is 10-year moving average, the data from http://www.cgd.ucar.edu/cas/catalog/climind/soI.signal.annstd.ascii) in 1960-2006 
which causes the droughts (Ropelewski et al., 1987), storms and floods all over the world (Ropelewski et al., 1987; Jones et al., 2001; Yan et al., 2011). This work indicates that, the precipitation change of the Laohugou glacier basin in the Qilian Mountains and the those sites on the northeastern Tibetan Plateau has an obviously positive correlation with ENSO during the past 50 years, although there is a relative lag period of 10 years (Figure 6). The Southern Oscillation Index (SOI) variation trend changed around 1970, which showed a decreasing trend after increasing in the period 1960-1970. But the precipitation trend change in the study area of the western Qilian Mountains and the northeastern Tibetan Plateau was observed around 1980. This shows the precipitation change of this region is very likely affected by ENSO. The change of ENSO may lead to the change of summer wind strength. Meanwhile, the study area is obviously affected by the westerly circulation (Figure 7). The effect of the East Asian summer monsoon (EASM) and the westerly circulation would lead to atmospheric precipitation change in the high elevation area of the Qilian Mountains, and then it acquires a certain degree of reflection in the ice core record. At the same time, the reconstructed precipitation showed no obviously positive correlation with the NAO, which will not be discussed here in detail any more.

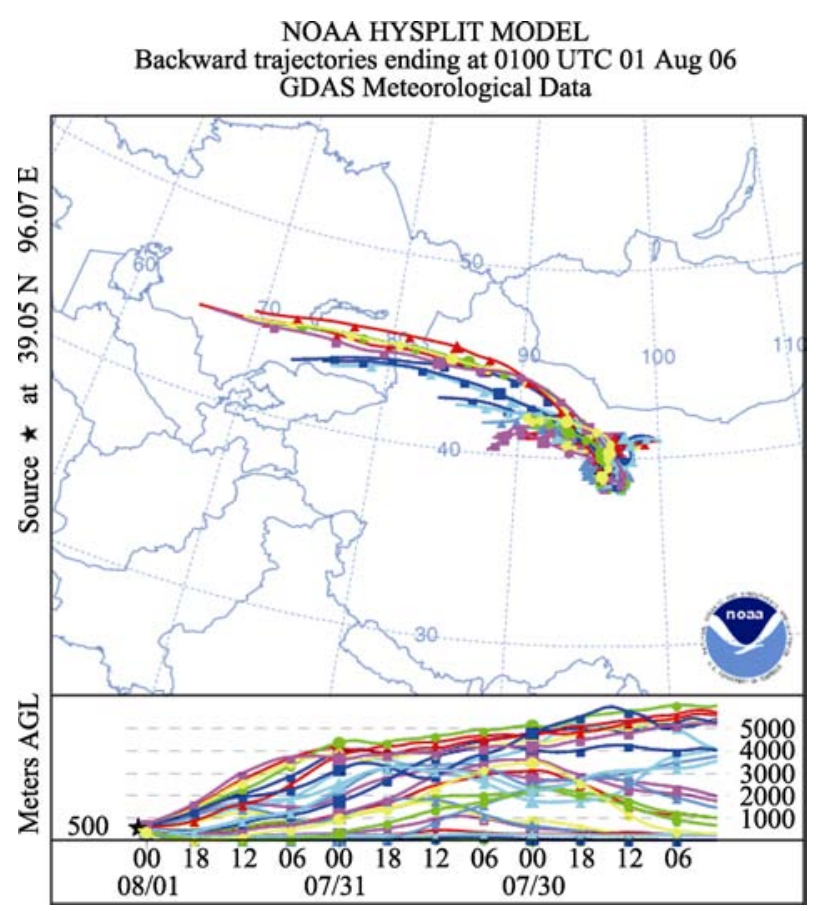

Figure 7 A typical example of a 3-day backward trajectory of air masses to the Laohugoug glacier basin in the summer of 2006 from the NOAA Hysplit Model

Precipitation of the western Qilian Mountains and the northeastern Tibetan Plateau increased firstly and then decreased over the past 50 years. It is likely caused by the change of water vapor transmission of the region, under the drive of global atmosphere in ENSO. Under this mechanism change, there is a relative lag period of about 10 years. We consider this effect probably exists. The lag effect of climate environment is often associated with the slow process of the mechanism of climate impact. The change of ENSO leads to the change strength of atmospheric circulation, and then it affects the precipitation change in different 
areas. Generally, such a change process is always slow. However, it is also affected by the regional environment and terrain factors, etc. Meanwhile, for the ice core record of high-altitude glacier areas, the complexity of the atmospheric precipitation and transformation in the high altitude area may cause the relative lag of the records. After an artificial remove of a decade relative lag, the correlation between ENSO and precipitation in the study area is significant with $R=0.56(P<0.01)$. This shows that such a mechanism is likely to be reliable. However, the understanding of such effect mechanism remains unclear (Gou et al., 2001; Fang et al., 2010; Wang et al., 2010; Xu et al., 2011), and further study needs to be carried out.

\section{Conclusions}

(1) During 1960-2006, the average precipitation of the Laohugou Glacier No.12 accumulation area is about $310 \mathrm{~mm}$, and the coefficient of variation of precipitation is $41 \%$. The precipitation of alpine glacier area showed an increasing trend from 1960 to 1980, while it is an obvious decreasing trend from 1980 to 2006. The precipitation change in glacier area has a good consistency with the observed precipitation change in the nearest low mountain weather station (Subei), and the correlation coefficient of $R=0.619(P<0.001)$. However, the precipitation of high mountain area is about 3 times more than that of the low mountains in Subei. There is no obvious positive correlation between the precipitations of ice core and the weather stations in piedmont plain of the Qilian Mountains. However, the correlation between temperature data of all surrounding research sites is significant. Such spatial difference also reflects the complexity of regional precipitation in mountain regions.

(2) The reconstructed precipitation of the Laohugou glacier basin is well corresponded with the net accumulation of the Dunde ice core, and the measured precipitation of multiple weather stations in the northeastern Tibetan Plateau, and the reconstructed precipitation of Delingha tree ring, and also the change of the PDSI (Palmer Drought Severity Index). However, the changing trend of precipitation at these sites is turned around 1980, and shows an obvious trend of firstly increasing and then decreasing. The adjacent PDSI drought index also indicates that, the drought-wet change result of the ice core record is reliable, as the drought index has showed an obvious decreasing trend since 1980, which is similar to that of the ice core accumulation record. Results of spatial analysis showed that, the reconstructed precipitation change of this work is of spatial representative for the precipitation change in the western Qilian Mountains.

(3) During the past 50 years, the precipitation change of the Laohugou Glacier area in the Qilian Mountains and the northeastern Tibetan Plateau had an obviously positive correlation with ENSO, although there was a relative lag period of 10 years, which implied that the change of local precipitation was likely affected by the regional change of water vapor transmission under the cycle of ENSO.

\section{References}

Cui Xiaoqing, Ren Jiawen, Qin Xiang et al., 2011. Climatic and environmental records within a shallow ice core at Laohugou Glacier No.12, Qilian Mountains. Journal of Glaciology and Geocryology, 33(6): 1521-1528. (in Chinese)

Dai A G, 2011. Characteristics and trends in various forms of the Palmer Drought Severity Index during 
1900-2008. Journal of Geophysical Research, 116: D12115.

Dai A, Trenberth K E, Qian T, 2004. A global data set of Palmer Drought Severity Index for 1870-2002: Relationship with soil moisture and effects of surface warming. Journal of Hydrometeorology, 5(6): 1117-1130, doi: 10.1175/JHM-386.1.

Dong Weimiao, An Chengbang, Zhao Yongtao et al., 2012.Variation of D/F records in historical documents of Hexi region during LIA and its mechanism. Arid Land Geography, 35(6): 946-951. (in Chinese)

Dong Zhiwen, Qin Dahe, Ren Jiawen et al., 2013.Variations in the equilibrium line altitude of Urumqi Glacier No.1, Tianshan Mountains, over the past 50 years. Chinese Science Bulletin, 58, doi: 10.1007/ s11434012-5524-1.

Du Wentao, Qin Xiang, Liu Yushuo et al., 2008.Variation of the Laohugou Glacier No.12 in the Qilian Mountains. Journal of Glaciology and Geocryology, 30(3): 373-379. (in Chinese)

Duan Keqin, Yao Tandong, Wang Ninglian, 2008. The difference in precipitation variability between the North and South Tibetan Plateaus. Journal of Glaciology and Geocryology, 30(5): 726-732. (in Chinese)

Fang K Y, Gou X H, Chen F H et al., 2010. Reconstructed droughts for the southeastern Tibetan Plateau over the past 568 years and its link ages to the Pacific and Atlantic Ocean climate variability. Climate Dynamic, 35: 577-585

Gou Xiaohua, Chen Fahu, Wang Yajun et al., 2001. Spring precipitation reconstructed in the east of the Qilian Mountain during the last 280 a by tree ring width. Journal of Glaciology and Geocryology, 23(3): 292-295. (in Chinese)

Hou Shugui, Qin Dahe, Wake C P et al., 1999. Change of net accumulation in glaciers of Everest from ice core. Chinese Science Bulletin, 44(21): 2336-2340. (in Chinese)

Hou Shugui, Qin Dahe, Yao Tandong et al., 2000. Recent change on net accumulation of ice cores in the Tibetan Plateau. Chinese Science Bulletin, 47(20): 1588-1591. (in Chinese)

Jones P D, Osborn T J, Briffa K R, 2001.The evolution of climate over the last millennium. Science, 292, 662-667.

Kang Xingcheng, Ding Liangfu, 1981. Relation of mass balance, ELA and climate in Tianshan Mountain and Qilian Mountain. Journal of Glaciology and Geocryology, 3(1): 53-56. (in Chinese)

Qin Dahe, Paul A Mayewski, Wake C P et al., 2000. Evidence for recent climate change from ice cores in the Himalayas. Annals of Glaciology, 31 (1): 153-158.

Ropelewski C, Jones P, 1987. An extension of the Tahiti-Darwin southern oscillation index. Mon. Weather Rev., 115: 2161-2165.

Shao Xuemei, Huang Lei, Liu Hongbing et al., 2004. Precipitation change since last millennium from tree ring in Delingha, Qinghai. Science in China (Series D), 34(2): 145-153. (in Chinese)

Sun J, Liu Y, 2012. Tree ring based precipitation reconstruction in the south slope of the middle Qilian Mountains, northeastern Tibetan Plateau, over the last millennium. Journal of Geophysical Research, 117, D08108, doi: 10.1029/2011JD017290.

Sun Weijun, 2012. Modeling of surface energy-mass balance on the Laohugou Glacier No.12 in the Qilian Mountains, China. Lanzhou: Doctor Dissertation of Cold and Arid Regions Environmental and Engineering Research Institute, Chinese Academy of Sciences. (in Chinese)

Thompson L G, Yao T, Thompson EM et al., 2000. A high-resolution millennial record of the South Asian Monsoon from Himalayan ice cores. Science, 289(5486): 1916-1919.

Wang Min, Zhou Caiping, Wu Liang et al., 2013. Wet-drought pattern and its relationship with vegetation change in the Qinghai-Tibetan Plateau during 2001-2010. Arid Land Geography, 36(1): 49-56. (in Chinese)

Wang N L, He J Q, Pu J C et al., 2010. Variations in equilibrium line altitude of the Qiyi Glacier, Qilian Mountains, over the past 50 years. Chinese Science Bulletin, 55(33): 3810-3817, doi: 10.1007/s11434-010-4167-3.

Xu G, Chen T, Liu X et al., 2011. Potential linkages between the moisture variability in the northeastern Qaidam Basin, China, since 1800 and the East Asian summer monsoon as reflected by tree ring $\mathrm{d}^{18} \mathrm{O}$. Journal of Geophysical Research, 116, D09111, doi: 10.1029/2010JD015053.

Yan H, Sun L, Oppo D W et al., 2011. South China Sea hydrological changes and Pacific Walker Circulation variations over the last millennium. Nature Communication, 2: 293.10.1038/ncomms1297.

Yao Tandong, Jiao Keqin, Yang Meixue et al., 1999. Precipitation change during past 400 years in Guliya ice core. Progress in Natural Science, 9(12): 126-165. (in Chinese)

Yao Tandong, Qin Dahe, Tian Lide et al., 1996a. Temperature and precipitation change during past 2 ka in Guliya ice core. Science in China (Series D), 26(4): 348-353. (in Chinese)

Yao Tandong, Thompson L G, Qin Dahe et al., 1996b. Variations in temperature and precipitation in the past 2000a on the Xizang Plateau: Guliya ice core record. Science in China (Series D), 39(4): 425-433.

Yao Tandong, Xie Zichu, Wu Xiaoling et al., 1990. Climatic record since Little Ice Age from Dunde ice core. Science in China (Series B), 11: 1196-1201. (in Chinese)

Zhang Yongjun, Kang Shichang, Qin Dahe et al., 2007. Annual accumulation and atmospheric circulation change in Geladandong ice core in Tibetan Platuen. Chinese Science Bulletin, 52(20): 2423-2427. (in Chinese) 